\title{
THERMAL LESION FORMATION AND DETERMINATION FOR EXTERNAL ULTRASOUND THERMAL THERAPY
}

\author{
HaO-Li Liu ${ }^{1}$, Yung-Yaw Chen ${ }^{1}$, JiA-Yush Yen ${ }^{2}$ and Win-Li Lin ${ }^{3}$ \\ 'Department of Electrical Engineering, ${ }^{2}$ Department of Mechanical Engineering, \\ ${ }^{3}$ Institute of Biomedical Engineering, National Taiwan University \\ Taipei, Taiwan
}

\section{ABSTRACT}

The purpose of this paper is to investigate the relationship between the formation of the thermal lesion and the major parameters of the external ultrasound heating systems, and to propose a useful thermal lesion determination procedure, which is capable of specifying the range of a thermal lesion by temperature feedback in external ultrasound thermal therapy. This work is based on an ideal ultrasound power deposition formed by an external ultrasound heating system and the temperature distribution is calculated by the transient bioheat transfer equation. A simplified model was employed to determine the heating pattern for four most important parameters. Through the simplified power expression, the property of a new parameter; T30o, which is defined as the maximal temperature corresponding to the thermal dose of 300 minutes, is also investigated. When the target volume is large enough such that the thermal conduction effect becomes negligible, the T300 value is almost independent of the system parameters and the heating strategies, and is dominated by the blood perfusion rate with a monotonic correlation. The method enables us to use feedback information in the ultrasound heating process and to pre-determine the heating range of the thermal lesion, which will be very useful in ultrasound treatment planning.

Biomed Eng Appl Basis Comm, 2003 (June); 15: 124-132.

\section{INTRODUCTION}

The aim of ultrasound thermal therapy [1-5] is to use high intensity, short-duration, focused ultrasound [6-8] to deliver enough energy into a specific tumor volume such that tissue necrosis is formed and the overheating of the intervening normal tissue can be avoided $[2,9]$. The external ultrasound heating is a noninvasive and very flexible modality for heating deep-

Received: June 2, 2003; Accepted: June 10, 2003 Correspondence: Prof. Yung-Yaw Chen, Department of Electrical Engineering, National Taiwan University, No.1, Sec. 4, Roosevelt Road, Taipei, Taiwan 106 E-mail: yychen@cc.ee.ntu.edu.tw seated tumors for its vast penetration and focusing ability. The major task in external ultrasound thermal therapy is to correctly form a thermal lesion on the targeted tumor volume. In practice, the thermal lesion cannot be visualized directly. Thermal dose distribution with a threshold value [10] is usually used to determine the effective region of thermal lesion.

The relationship between the size of the thermal lesion and the thermal dose distribution with threshold values has been studied in literatures. ter Haar et al. [27] performed high intensity, focused ultrasound trail in-vivo and exercised liver sample in-vitro to investigate the thermal lesion patterns under different sonication time and heating power. It was found that the thermal lesion enlarged with increasing sonication time and heating power. The conclusion was consistent 
with Hutchinson and Hynynen's [11] study for noninvasive ultrasound thermal therapy using phased arrays. Moreover, it was also found that a larger blood perfusion rate results in a smaller thermal lesion size in [2], while the shape as well as the size of the thermal lesion varies with different arrangement of external ultrasound heating systems [12].

Although there are many discussions on thermal lesion formation from the existing literatures, few studies focused on its relationship with the heating system arrangement, such as the size of the acoustic window, the focal depth, the attenuation coefficient and the size of the focal zone. These indices were found to be the major factors to form various power depositions and the associated heating patterns in external ultrasound heating systems. In addition, the determination of the sonication time and the heating power for a desired thermal lesion volume is difficult due to its complicated correlations to the abovementioned system parameters.

The objectives of this research are to investigate the relationships between the formation of the thermal lesion and the major parameters of the external ultrasound heating systems, and to propose a procedure for thermal lesion formation and determination. Furthermore, the procedure will be shown to provide a proper and simple heating configuration for thermal therapy. In order to focus on the study to the parameters determinations in thermal lesion formation, the Specific Absorption Ratio (SAR) model is employed to approximate the absorbed power density generated by practical external ultrasound thermal therapy systems. The approach has been widely used and verified by many researchers in a number of experiments $[13-15,16,17]$. The temperatures as well as the thermal dose distributions are calculated to examine the relationships between the system indices and the thermal lesion region, which is identified by a region with a threshold value of 300 minutes in thermal dose. Studies show that the heating temperature corresponding to a threshold value of thermal dose is only affected by the blood perfusion rate when the focal zone diameter is large than $2 \mathrm{~cm}$. This property can be used in thermal lesion determination and consequently provides a guideline in thermal therapy design. Three design examples with different tumor volume settings are studied and both show satisfactory results on lesion determination. This paper provides a useful reference for researchers attempting to design the externally ultrasound thermal therapy system for deep-seated large tumors and offers a simple but useful clinical treatment lesion determination scheme.

\section{MATERIALS AND METHDS}

\subsection{Specific Absorption Rate (SAR) Model}

Fig. 1 shows the geometrical relationship between transducer and treatment portion in external ultrasound-heating model. The external ultrasound transducer is assumed to create an acoustic window of diameter $\mathrm{d}(0)$ at the origin. The targeted tumor region is at distance $Z_{t}$ with a diameter $\mathrm{d}\left(Z_{t}\right)$. The $z$-axis is referred to be the depth of penetration and is vertical to the skin surface, which is located at the origin of the $z$-axis. The ultrasound wave is assumed to propagate in straight line, and to converge and focus on the targeted tumor region at $Z=Z_{t}$, and diverge beyond this focal depth. At $Z=0 \mathrm{~cm}$, the area with diameter $d(0)$ is referred to be the acoustic window of the ultrasonic beam. The deposition of ultrasonic intensity at each depth was considered to be a distribution symmetrical along the $\mathrm{z}$-axis, i.e. the power deposition can be modeled to be two dimensional in the radial (R-axis) and the depth ( $\mathrm{Z}$-axis) directions. This arrangement provides a relatively simple but realistic approximation in evaluating the power deposition and the thermal dose distribution to avoid over-complicated calculations.

The ultrasonic power attenuates exponentially as it propagates through the tissue. Assuming that the ultrasonic power intensity is not too large to cause wave distortions and all the attenuated energy is absorbed by the tissue, the ultrasonic power at depth $z$ $\mathrm{cm}, \mathrm{Q}(\mathrm{z})$, and the associated power intensity, $\mathrm{I}(\mathrm{z})$, can be described by:

$$
\begin{aligned}
& Q(z)=Q(0) \cdot e^{-2 \mu \cdot z} \\
& I(z)=\frac{Q(z)}{A(z)}
\end{aligned}
$$

where $\mathrm{Q}(0)$ is the total power propagating through the acoustic window, $\mu$ is the attenuation coefficient and $\mathrm{A}(\mathrm{z})$ represents the cross-sectional area of the conical power region at depth $\mathrm{z} \mathrm{cm}$. From Fig. 1, it is clear that

$$
\begin{aligned}
& A(z)=\pi[d(z) / 2]^{2} \\
& d(z)=d\left(z_{t}\right)+\left(d(0)-d\left(z_{t}\right)\right) \cdot\left|z-z_{t}\right| z_{t}
\end{aligned}
$$

where $d(z)$ is the diameter of the conical power region at depth $z \mathrm{~cm}$. The acoustic attenuation coefficient $\mu$ depends on the driving frequency, and is approximately $5 \mathrm{~Np} / \mathrm{m}$ at $1 \mathrm{MHz}$ and $10 \mathrm{~Np} / \mathrm{m}$ at $2 \mathrm{MHz}$ [18].

The specific absorption rate (SAR) is defined to be the absorbed power density (q) in soft tissue, and can be calculated by: 


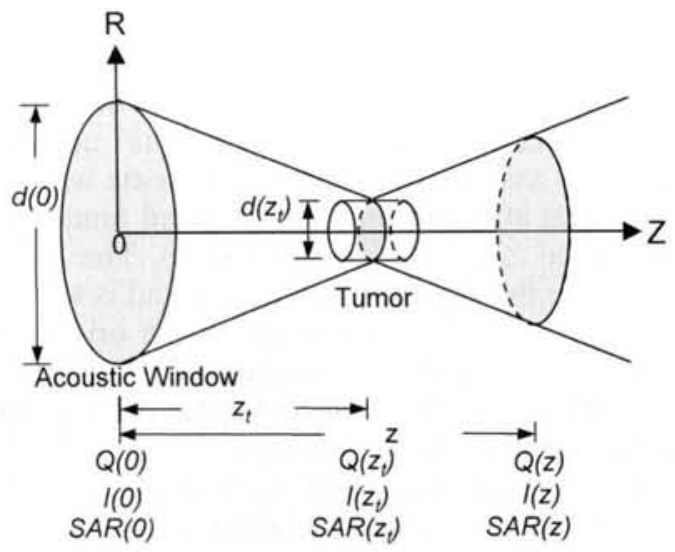

Fig. 1 Schematic diagram of the geometry studied for the distribution of SAR ratio in the tissue for external ultrasound thermal therapy.

$\operatorname{SAR}(\mathrm{z})=2 \alpha \mathrm{I}(\mathrm{z})$

where $\alpha$ is the absorption coefficient. Moreover, the SAR ratio (SR) between the SAR values at depth $z$ and the focal depth $Z_{t}$ can be calculated as:

$$
\operatorname{SR}\left(z ; z_{t}\right)=\frac{\operatorname{SAR}(z)}{\operatorname{SAR}\left(z_{t}\right)}=\frac{2 \alpha I(z)}{2 \alpha I\left(z_{t}\right)}=\frac{d^{2}\left(z_{t}\right)}{d^{2}(z)} \cdot e^{-2 \mu\left(z-z_{t}\right)}
$$

Once the SAR value at $\mathrm{z}_{t}$ is determined, the SAR value at depth $\mathrm{z}$ can be calculated by:

$$
\operatorname{SAR}(z)=\operatorname{SAR}\left(z_{t}\right) \cdot \frac{d^{2}\left(z_{t}\right)}{d^{2}(z)} \cdot e^{-2 \mu\left(z-z_{t}\right)}
$$

In Eq. (7), the ratio of the cross-sectional areas between the focal zone at $z=Z_{t}$ and the acoustic window at $z=0$ (i.e. $\mathrm{d}^{2}\left(Z_{t}\right) / \mathrm{d}^{2}(0)$ ) is defined to be the Geometrical Gain (GG) for the SAR model. The corresponding temperature distribution can be then computed from the SAR(z) distributions in the following section.

\subsection{Temperature and Thermal Dose Calcul- ation}

The tissue temperature response, $\mathrm{T}$, is calculated using the well-known bio-heat transfer equation [19]:

$$
\rho c_{t} \frac{\partial T}{\partial t}=k \nabla^{2} T-w_{b} c_{b}\left(T-T_{a r}\right)+q
$$

where $c_{t}$ and $c_{b}$ are the specific heats of tissue and blood (both set to be $3770 \mathrm{~J} / \mathrm{kg} /{ }^{\circ} \mathrm{C}$ ), $\mathrm{k}$ is the thermal conductivity of tissue $\left(0.56 \mathrm{~W} / \mathrm{m} /{ }^{\circ} \mathrm{C}\right), W_{b}$ is the blood perfusion rate, and $\mathrm{T}_{\mathrm{ar}}$ is the arterial blood temperature $\left(37^{\circ} \mathrm{C}\right)$. This equation is solved using a numerical finite difference method with all boundary and initial conditions set to $37^{\circ} \mathrm{C}$. The time step and the grid spacing in the $\mathrm{x}-, \mathrm{y}$ - and $\mathrm{z}$-directions are $50 \mathrm{~ms}, 0.5$ $\mathrm{mm}, 0.5 \mathrm{~mm}$ and $1 \mathrm{~mm}$, respectively.

The thermal dose (TD), in terms of equivalent minutes at $43^{\circ} \mathrm{C}$, is used to estimate the necrosed tissue volume, and is calculated using the following equation $[10,20-22,24,25]$ :

$$
T D=\int_{t_{0}}^{t_{f}} R^{(T-43)} d t \approx \sum_{t_{0}}^{t_{f}} R^{(T-43)} \Delta t
$$

where $\mathrm{R}=2$ for $\mathrm{T} \geq 43^{\circ} \mathrm{C}, \mathrm{R}=4$ for $37^{\circ} \mathrm{C}<\mathrm{T}<43^{\circ} \mathrm{C}$, $\Delta t$ is the time step, and to and tf represent the initial and the final times, respectively. The TD value required for total necrosis ranges from 25 to 240 minutes for brain to muscle tissues $[8,24]$. In this study, a value of TD $=300$ minutes is chosen as the threshold for complete heating [26].

The absorbed power density at the focal depth in all five cases were set to be $16 \mathrm{~W} \mathrm{~cm} \mathrm{~cm}^{-3}$ with heating time of 6 seconds throughout the study unless otherwise mentioned. In our simulations, such transducer power will provide a maximal temperature about $60^{\circ} \mathrm{C}$ during the heating process. The computation of temperature profiles is terminated at time of 600 s, which is sufficient to determine the TD distribution precisely. The SAR ratio distributions along the central $\mathrm{z}$-axis with the parameter settings in Table 1 are shown in Fig. 2(a). The corresponding temperature distributions at the end of heating session (at $\mathrm{t}=6 \mathrm{~s}$ ) and the thermal dose distributions (at $\mathrm{t}=$ 600 s) are shown in Fig. 2(b) and Fig. 2(c) respectively. The maximal thermal dose with equal absorbed power density and heating time in five cases are different, which is caused by various thermal conduction effects from different SAR distributions. It can be observed that the maximal thermal dose is smaller if the SAR distribution has a sharper profile at the focal depth. The cross-sectional areas with TD value 300 minutes in Fig. 2(c) for five cases in Table 1 are different. Their dimensions increase as $\mu$ (Case 1 vs. Case 4 ) and $z_{t}$ (Case vs. Case 2) increases and as geometrical gain (Case 1 vs. Case 3 and 5) decreases. It is also found that to deliver the same absorbed power density to heat the focal zone with diameter $\mathrm{d}\left(Z_{t}\right) \mathrm{cm}$ at focal depth $\mathrm{z}_{t}$ $\mathrm{cm}$, the propagated ultrasound power attenuate more seriously and more ultrasound power will be absorbed in front of the treatment target then cause the pre-focal overheating. To prevent this, the acoustic window $(d(0))$ can be enlarged to an appropriate geometrical gain setting (Lin et al., 1999).

\subsection{Thermal Lesion Determination Using $T_{300}$}


Table 1 . The focal depth $\left(Z_{t}\right)$, focal zone diameter $\left(\mathrm{d}\left(Z_{t}\right)\right)$, acoustical attenuation $(\mu)$ and acoustic window (d(0)) settings studied for the distributions of $S A R$ ratio and the resulting temperature and thermal dose (case 1 is regarded as a typical setting).

\begin{tabular}{lcccc} 
Case & $Z_{\boldsymbol{t}}(\mathbf{c m})$ & $\mathbf{d}\left(\boldsymbol{Z}_{t}\right)(\mathbf{c m})$ & $\boldsymbol{\mu}(\boldsymbol{N p} / \mathbf{m})$ & $\mathbf{d}(\mathbf{0})(\mathbf{c m})$ \\
\hline $\mathbf{1}$ & 10 & 2 & 5 & 10 \\
$\mathbf{2}$ & 15 & 2 & 5 & 10 \\
$\mathbf{3}$ & 10 & 2 & 5 & 10 \\
$\mathbf{4}$ & 10 & 4 & 15 & 10 \\
$\mathbf{5}$ & 10 & 2 & 5 & 7
\end{tabular}

The temperature at the end of the ultrasound heating always corresponds to the maximum value in the temperature profile and seems to be related to the thermal dose values. It is, therefore, possible to determine the range of thermal lesion from temperature observations. The temperature distribution within the target volume will increase as the transducer continuously providing the energy and reach its maximum profile at the time the heating is terminated. The corresponding maximum temperature at this point is then defined to be the temperature of thermal dose value 300 minutes and is denoted by $\mathrm{T}_{300}$. The observation of $\mathrm{T}_{300}$ can simply follow the arrow line between Figure 2(b) and 2(c). For all the five cases discussed in Table 1 , the value of $\mathrm{T} 300$ is about $51^{\circ} \mathrm{C}$ both in the pre-focal and post-focal regions and seems to be insensitive to the variation of parameters. The value of $T_{300}$ along the central $z$-axis is shown in Figure 2(a)-(c). Fig. 2(d) shows the r-z temperature distribution of case 1 at the end of heating ( 6 seconds), and the dashed line represents the computed thermal dose contour of TD value 300 minutes. Possible factors to $T_{300}$ value include system parameter, blood perfusion rate, absorbed power density, heating rate, and absorbed power density. This will be analyzed in Sec. 3.1 and 3.2.

\section{RESULTS}

\subsection{Effect of Different System Parameters}

In this analysis, the typical values of the four systems parameters $\mathrm{z}, \mathrm{d}\left(\mathrm{z}_{t}\right), \mu$, and $\mathrm{d}(0)$ are set to be $10 \mathrm{~cm}, 2 \mathrm{~cm}, 5 \mathrm{~Np} / \mathrm{m}$ and $10 \mathrm{~cm}$, respectively. The four parameters are solely altered to individually examine the effects the $T_{300}$ value, and the corresponding thermal doses are shown in Fig. 3. From this figure, it can be observed that the size of the TD $=300 \mathrm{~min}$. contour increases with $\mu$ and $Z_{t}$. The observed $T_{300}$

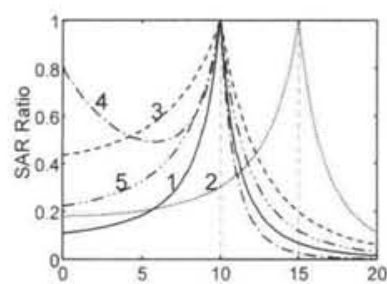

(a)

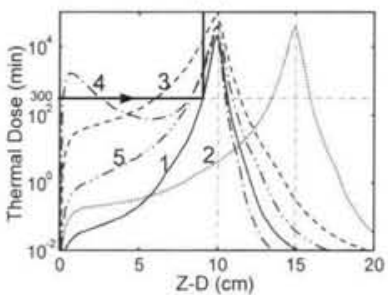

(c)

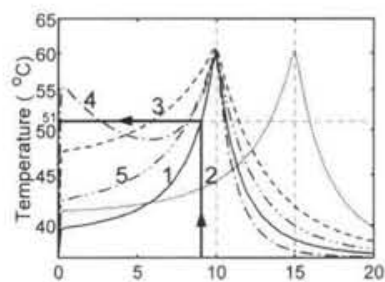

(b)

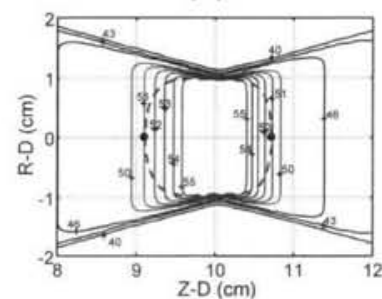

(d)
Fig. 2 (a) The SAR ratio distributions with the parameter setting listed in Table 1, (b) heating temperature distributions at the time heating power is turned off (6s) and (c) thermal dose distributions when the parameters in Table 1 is used. Dashed lines in (b) and (c) represent the TD $=\mathbf{3 0 0}$ minutes and temperature at $51^{\circ} \mathrm{C}$, respectively. (d) shows the temperature distribution in the transverse plane when the heating power is turned off (parameter settings of case 1 in Table 1 is used). Dashed contour represents the resulting thermal dose with $\mathbf{3 0 0}$ minutes.
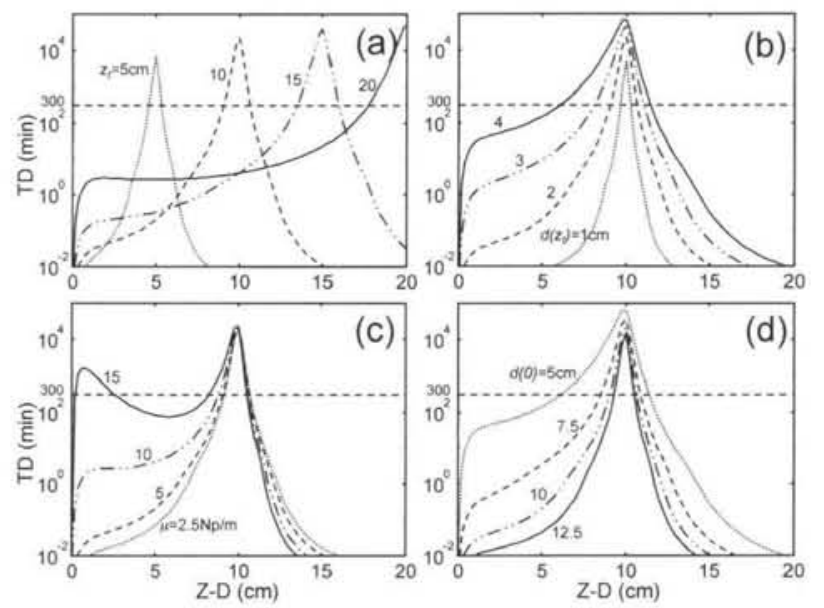

Fig. 3 Thermal dose distributions along central z-axis at (a) $Z_{t}$ is set to $5 / 10 / 15 / 20 \mathrm{~cm}$, (b) $\mathrm{d}\left(Z_{t}\right)$ is set to $1 / 2 / 3 / 4 \mathrm{~cm}$, (c) $\mu$ is set to $2.5 / 5 / 10 / 15 \mathrm{~Np} / \mathrm{m}$ and (d) $d(0)$ is set to $5 / 7.5 / 10 / 12.5 \mathrm{~cm}$ when the other parameters are set to case 1 in Table 1. 
value are found ranging from $51.1^{\circ} \mathrm{C}$ to $51.3^{\circ} \mathrm{C}$ except for the case of small $\mathrm{d}\left(Z_{t}\right)$. The exception seems to be from the small focal zone diameter, which causes the value of $T_{300}$ along the central $z$-axis easily affected by thermal conduction effect.

\subsection{Effect of Different Blood Perfusion Rates and Absorbed Power Densities}

Blood perfusion rate $\left(W_{b}\right)$ is also a critical factor affecting the thermal dose distribution and the contour of $\mathrm{T}_{300}$. For illustrations, different blood perfusion rates of $0.5 / 2 / 5 / 10 / 20 \mathrm{~kg} / \mathrm{m}^{3} / \mathrm{s}$ and $\mathrm{d}\left(Z_{t}\right)$ of $0.5 / 1.0 / 1.5 / 2 / 3 / 4$ $\mathrm{cm}$ were selected to depict the various conditions of human body. The corresponding $\mathrm{T}_{300}$ values in the prefocal area on the central z-axis are shown in Fig. 4. It can be found that $T_{300}$ decreased monotonically with increasing $\mathrm{d}\left(Z_{t}\right)$, and converged to steady values with $\mathrm{d}\left(Z_{t}\right)$ larger than 2 to $3 \mathrm{~cm}$. The values of $\mathrm{T}_{300}$ with the blood perfusion rates of $0.5,2,5,10,20 \mathrm{~kg} / \mathrm{m}^{3} / \mathrm{s}$ converged to $49.2^{\circ} \mathrm{C}, 51.2^{\circ} \mathrm{C}, 52.7^{\circ} \mathrm{C}, 53.8^{\circ} \mathrm{C}$ and $54.8^{\circ} \mathrm{C}$, respectively. It is reasonable that higher blood perfusion rate acts as a strong heat sink, and takes the energy away faster. The result is higher temperature elevation required to achieve the thermal dose threshold of 300 minutes, which means the value of $\mathrm{T}_{300}$ is higher.

When $\mathrm{d}\left(Z_{t}\right)$ is smaller than $2 \mathrm{~cm}$, the corned-shape power profile at the focal depth zt is narrower, and hence the value of $T_{300}$ is affected by both the blood perfusion rate and thermal conduction effect. On the other hand, When the focal zone diameter $\mathrm{d}\left(Z_{t}\right)$ is large enough (approximately $2 \mathrm{~cm}$ in diameter), the $T_{300}$ is dominantly affected by the blood perfusion rate, and the thermal conduction effect can be neglected.

The absorbed power density is also an important factor for T 300 values. With constant heating time $(6 \mathrm{~s}$ in our examples), higher power intensity setting provides

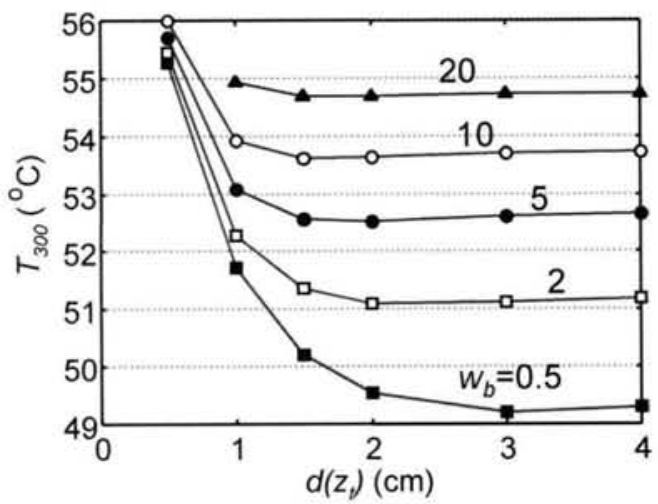

Fig. 4 Relationship between $T_{300}$ and the focal region diameter $\mathrm{d}\left(Z_{t}\right)$ when the blood perfusion varies from 0.5 to $20 \mathrm{~kg} / \mathrm{m}^{3} / \mathrm{s}$. a higher temperature elevation, which results in higher peak values in thermal dose distributions and bigger thermal lesions. Fig. 5(a) and Fig. 5(b) show the relationships between $T_{3} 00$ and different values of absorbed power density with constant heating time, different blood perfusion rates, and $\mathrm{d}\left(Z_{t}\right)$ of $0.5 \mathrm{~cm}$ and $2 \mathrm{~cm}$ respectively. The value of $\mathrm{T} 300$ decreased monotonically with increasing absorbed power density as shown in Fig. 5(a), while the T300 values showed no apparent changes as the absorbed power intensity varied in Fig. 5(b). The difference between Fig. 5(a) and $5(b)$ is from the size of $d\left(Z_{t}\right)$. Similar to the conclusion above, the conduction effect is strong when $\mathrm{d}\left(Z_{t}\right)$ is small, while the blood perfusion rate becomes dominant when $\mathrm{d}\left(Z_{t}\right)$ is large enough.

The corresponding thermal dose distributions with the power density of 18 and $38 \mathrm{~W} / \mathrm{cm}^{3}$ and the blood perfusion rates of 0.5 and $20 \mathrm{~kg} / \mathrm{m}^{3} / \mathrm{s}$ are shown in Fig. $5(\mathrm{c})$ with $\mathrm{d}\left(Z_{t}\right)$ of $0.5 \mathrm{~cm}$ and in Fig. 5(d) with $\mathrm{d}\left(Z_{t}\right)$ of $2 \mathrm{~cm}$. It was found that the thermal dose distributions changed when the absorbed power density or blood perfusion are different. The absorbed power density had a greater influence to the thermal dose distributions than the blood perfusion rate. We also found that with smaller $\mathrm{d}\left(Z_{l}\right)$ and smaller power density, diameter of the induced necrosis volume decreases and $T_{300}$ increases from the thermal conduction effect.

\subsection{Effect of Different Heating Rates}

In real thermal therapies, different heating strategies are usually determined heuristically. The heating strategy in our paper is referred to the determination of heating power level and heating time. Even for constant energy settings (i.e., constant product of heating power and heating time), different heating temperature patterns and thermal lesions are usually formed. In this section, the values of $\mathrm{T}_{300}$ under different heating strategies are discussed and listed in Table 2. It is found that $T_{300}$ values maintain consistent results under different heating strategies with the same blood perfusion rate.

\subsection{Thermal Lesion Determination Procedure}

According to the above analysis, it is concluded that the value of $T_{300}$ is only determined by the blood perfusion rate when $\mathrm{d}\left(Z_{t}\right)$ is larger than $2 \mathrm{~cm}$. The property can be used to perform thermal lesion coverage determination by controlling the temperature of the selected target points to reach the proper $\mathrm{T}_{300}$ value. To determine the thermal lesion dimension, at first, two target points on the heating volume's boundary are set, one is ahead and the other is behind. Next, it is only to design the heating pattern, which can 


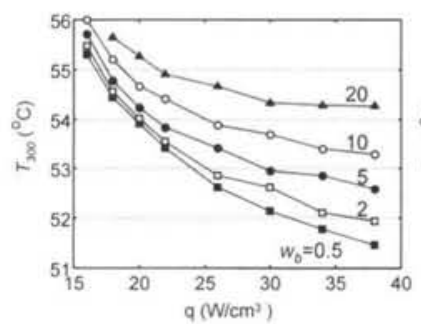

(a)

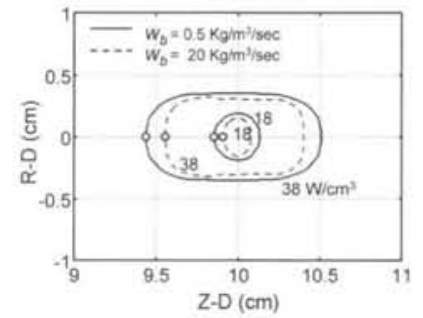

(c)

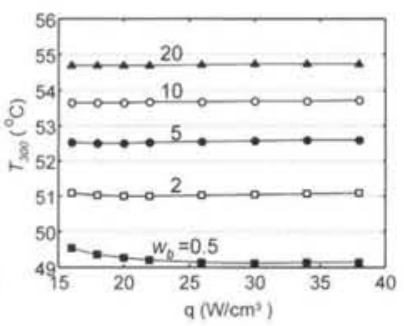

(b)

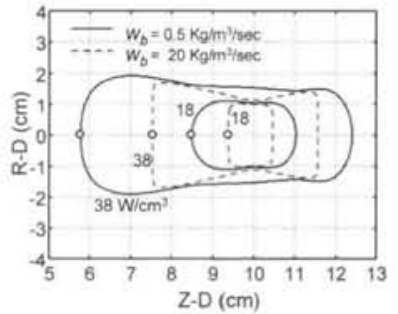

(d)
Fig. 5 Relationship between $T_{300}$ and the absorbed power density at focal depth when the blood perfusion rate is varied from 0.5 to $20 \mathrm{~kg} / \mathrm{m}^{3} / \mathrm{s}$ and $\mathrm{d}\left(Z_{t}\right)$ is set to (a) $0.5 \mathrm{~cm}$ and (b) $2 \mathrm{~cm}$. (c) and (d) depict the respective thermal lesions under different absorbed power density $\left(18\right.$ and $\left.38 \mathrm{~W} / \mathrm{cm}^{3}\right)$ and blood perfusion $\left(0.5\right.$ and $\left.20 \mathrm{~kg} / \mathrm{m}^{3} / \mathrm{s}\right)$ under $\mathrm{d}\left(Z_{l}\right)$ is set to (c) $0.5 \mathrm{~cm}$ and (d) $2 \mathrm{~cm}$.

deliver the same absorbed power density level onto these two target points and heat until reach the value of $\mathrm{T}_{300}$. The overall thermal lesion determination procedure is as follows:

1. Determine $\mathrm{z}_{t}$ and $\mathrm{d}\left(Z_{t}\right)$ to completely cover the target tumor. Moreover, according to the transducer and the driving frequency, the $m$ and $\mathrm{d}(0)$ and be also determined. Here, the treatment volume must be larger than $2 \mathrm{~cm}$ in diameter to be eligible for our approach.

2. The front and rear boundaries of the target volume along the central $z$-axis are defined as the front target and rear target points.

3 . Apply the simplified SAR model to roughly estimate the power deposition. Note that since the selected pair $\left(Z_{t}, \mathrm{~d}(0)\right)$ is not unique, therefore, a suitable $z t$ and $\mathrm{d}(0)$ should be determined to offer enough geometrical gain (GG). A GG value larger than 10 is suggested to prevent the thermal lesion extension problem.

4. With the given blood perfusion of the tissue, determine the value of T300 according to Fig. 6 .

5. Choose a heating power of the ultrasound thermal therapy system, which can offer the maximal absorbed power density over $20 \mathrm{~W} / \mathrm{cm}^{3}$ (according to the result shown in Fig. 5(b)).
Table 2. T300 under different heating strategies and different blood perfusion rates $\left(2,5\right.$ and $10 \mathrm{~kg} \mathrm{~m}^{-3}$ $\left.\mathbf{s}^{-1}\right)$.

\begin{tabular}{ccccc} 
Case & $\begin{array}{c}\mathbf{q} \\
\left(\mathbf{W} / \mathbf{c m}^{\mathbf{3}}\right)\end{array}$ & $\begin{array}{c}\text { Heating time } \\
(\mathbf{s})\end{array}$ & $\begin{array}{c}\mathbf{W b} \\
\left(\mathbf{k g} / \mathbf{m}^{3} / \mathbf{s}\right)\end{array}$ & $\begin{array}{c}\mathbf{T} 300 \\
\left({ }^{\circ} \mathbf{C}\right)\end{array}$ \\
\hline $\mathbf{1}$ & 20 & 5 & 2 & 51.1 \\
$\mathbf{2}$ & 10 & 10 & 2 & 51.1 \\
$\mathbf{3}$ & 10 & 15 & 2 & 51.0 \\
$\mathbf{4}$ & 20 & 5 & 5 & 52.5 \\
$\mathbf{5}$ & 10 & 10 & 5 & 52.5 \\
$\mathbf{6}$ & 10 & 15 & 5 & 52.6 \\
$\mathbf{7}$ & 20 & 5 & 10 & 53.6 \\
$\mathbf{8}$ & 10 & 10 & 10 & 53.6 \\
$\mathbf{9}$ & 10 & 15 & 10 & 53.5
\end{tabular}

6. Start heating the target volume using the determined power distribution. Turn off the heating power when the temperature at the front target point reaches $T_{300}$. Note that the treatment time will be shorter if the heating power chose in step 6 is larger.

7. Finally, the cumulative thermal dose distribution will roughly fit the target volume.

\subsection{Control Examples}

In order to show the validity of our thermal therapy design procedures, three cases with various tumor sizes are illustrated in the following section. In all three cases, the shape of the tumor is assumed to be of the cylindrical type.

In the first case, the cylindrical type treatment region with $2-\mathrm{cm}$ wide, $2-\mathrm{cm}$ thickness at the depth of $7 \mathrm{~cm}$ was assumed. The tumor diameter $\mathrm{d}\left(Z_{t}\right)$ is set to be $2 \mathrm{~cm}$, and $\mathrm{zt}, \mathrm{d}(0)$ and $\mathrm{m}$ were selected to be $7.5 \mathrm{~cm}$, $8 \mathrm{~cm}$ and $10 \mathrm{~Np} / \mathrm{m}$, respectively. The resulting geometrical gain is 16 , which is large enough to provide an appropriate geometric relation. The tissue property is assumed to be the same as in the previous cases except the blood perfusion was set to be 2 $\mathrm{kg} / \mathrm{m}^{3} / \mathrm{s}$. In order to evaluate the validity of using $T_{300}$ information for performing the thermal therapy under different heating strategies, the maximal absorbed power density were set to be $2 \mathrm{~W} / \mathrm{cm}^{3}$ and $32 \mathrm{~W} / \mathrm{cm}^{3}$ respectively. T 300 was determined to be $51.2^{\circ} \mathrm{C}$ according to Fig. 5. The front and rear target points are selected from the SAR distribution along the central $\mathrm{z}$-axis according to the above-mentioned procedure, where the SAR distribution can be found from the calculation of equation 6 and 7 . The heating power was turned off when the temperature of the front target 
point reached the set $T_{300}$ value, and the heating time on $2 \mathrm{~W} / \mathrm{cm}^{3}$ and $32 \mathrm{~W} / \mathrm{cm}^{3}$ were $52.6 \mathrm{~s}$ and $3.2 \mathrm{~s}$, and The $\mathrm{r}-\mathrm{z}$ thermal dose distributions are shown in Fig. $6(\mathrm{a})$ and $6(\mathrm{~b})$. The contours with $1,10,100$ and 300 minutes were plotted using real lines, and the regions enclosed by the dashed lines represent the region with the absorbed power densities larger than the power at the front and the rear target points. From Fig. 6, it shows that the thermal lesion coverage generated by different heating strategies is different. Thermal lesion formed by lower power density is smaller, which is due to the thermal conduct effect under the longer treatment time. However, the effect is not very significant to the central portion of the heating volume and the thermal lesion regions in both cases are pretty good results.

At second, a case of small tumor $\left(\mathrm{d}\left(Z_{t}\right)<2 \mathrm{~cm}\right)$ is shown with a cylindrical type treatment region of $1 \mathrm{~cm}$ in width, $1 \mathrm{~cm}$ in thickness and $7.5 \mathrm{~cm}$ in depth. The rest of the parameters are the same as the above case. The heating times on $2 \mathrm{~W} / \mathrm{cm}^{3}$ and $32 \mathrm{~W} / \mathrm{cm}^{3}$ are $62.7 \mathrm{~s}$ and $3.8 \mathrm{~s}$, and the respective thermal lesions are formed and shown in Fig. 7(a) and 7(b). It indicates that, since the heating volume is not large enough, the temperature on the target points are strongly affected, and the thermal lesions cannot be correctly determined.

The third case shows a cylindrical type treatment region with $3-\mathrm{cm}$ wide, $3-\mathrm{cm}$ thickness and $7-\mathrm{cm}$ depth was assumed. In order to show the effect of the acoustic window $d(0)$ on the coverage of the thermal lesion, $\mathrm{d}(0)$ is set to be $10 \mathrm{~cm}$ and $14 \mathrm{~cm}$, which provides geometrical gains of 11.1 and 21.8 respectively. The maximal absorbed power densities are both set to be $16 \mathrm{~W} \mathrm{~cm}^{-3}$, and other parameter settings are identical to above cases. The SAR ratio distributions are shown in Fig. 8(a). In order to fit the

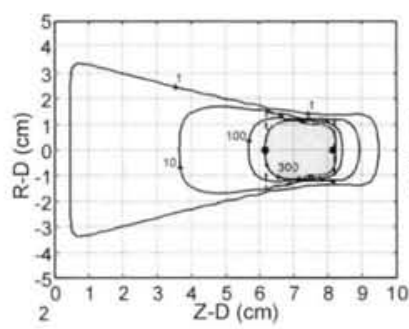

(a)

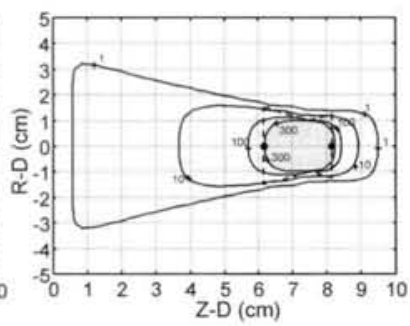

(b)
Fig. 6 Thermal dose distributions of the designed SAR ratio with the maximal absorbed power density set to (a) 2 and (b) $32 \mathrm{~W} / \mathrm{cm}^{3}$ under $\mathrm{d}\left(Z_{t}\right)=2$ $\mathrm{cm}$. The dashed lines are the regions with the absorbed power densities larger than the power on the two target points. Dots on the contours represent the "front target point" and "back target point" respectively in each figure.

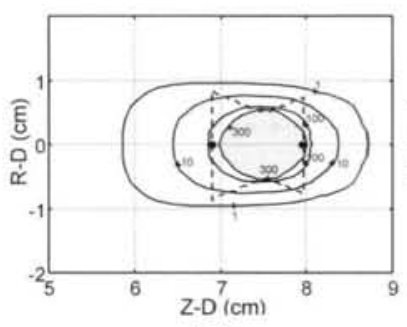

(a) (b)

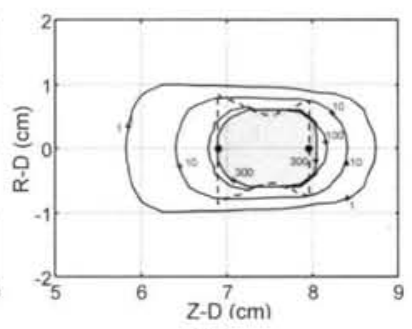

Fig. 7 Thermal dose distributions of the designed SAR ratio with the maximal absorbed power density set to (a) 2 and (b) $32 \mathrm{~W} / \mathrm{cm}^{3}$ under $\mathrm{d}\left(Z_{l}\right)=1$ cm.

SAR ratio curve to form a $3-\mathrm{cm}$ thickness region correctly, the selected positions of target points for both cases are slightly different. The heating times are $6.45 \mathrm{~s}$ when $\mathrm{d}(0)=10 \mathrm{~cm}$, and $9.4 \mathrm{~s}$ when $\mathrm{d}(0)=14 \mathrm{~cm}$. After heating the target points to the pre-determined T 300 value, the formed thermal lesions are shown in Fig. 8(b) and 8(c), respectively, with successful thermal lesion determination results.

\section{DISCUSSION}

In this paper, a useful thermal lesion determination procedure is proposed, which is capable of specifying the range of a thermal lesion by temperature feedback in external ultrasound thermal therapy. The method enables us to use feedback information in the ultrasound heating process and to pre-determine the heating range of the thermal lesion, which will be very useful in ultrasound treatment planning.

In this analysis, the SAR model is used to determine the parameters in the ultrasound heating setup, and provides a relatively simple expression of power deposition with four most important parameters. Through the simplified power expression, the property of a new parameter, $T_{300}$ can be observed. Specifically, when the target volume is large enough (with $\mathrm{d}\left(Z_{t}\right)$ larger than $2 \mathrm{~cm}$ ) such that the thermal conduction effect becomes negligible, T300 defined on the central $\mathrm{z}$ axis is almost independent of the system parameters $\left(\mathrm{d}(0), Z_{t} \mu\right)$ and the heating strategies (different absorbed power density setting and heating time), and is dominated by the blood perfusion rate with a monotonic correlation.

Based on the observations, two target points associated with the $T_{300}$ are selected and used for temperature feedback. Simulations show that the thermal lesions resulted from our heating procedure can be accurately determined and bounded by the two defined target points along central $\mathrm{z}$ axis and the size of $\mathrm{d}\left(Z_{t}\right)$ along radial axis, and is almost independent of 


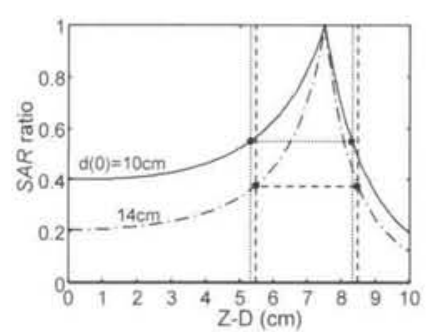

(a)

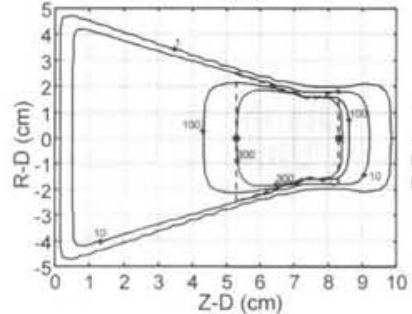

(b)

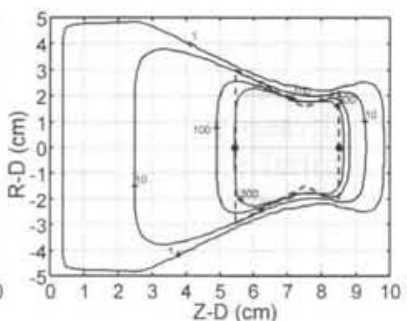

(c)
Fig. 8 (a) the designed SAR ratio distributions with $d(0)=10$ and $14 \mathrm{~cm}$. (b) and (c) are the respective thermal dose distributions, while the absorbed power densities are both set to $16 \mathrm{~W} / \mathrm{cm}^{3}$.

different combination of heating strategies.

In clinical treatment, our thermal lesion determination procedure will be quite useful, since it provides a feedback configuration that gives a more reliable therapeutic session and enhances the treatment quality. Moreover, independency to different heating strategies of the procedure will reduce the necessity of precise power control in practical system operations.

\section{CONCLUSION}

In conclusion, a thermal lesion determination scheme is proposed to offer an easy but useful guideline to precisely heat the selected deep-seated tumors. The key factor, $\mathrm{T}_{300}$ in the proposed scheme, is only affected by blood perfusion rate while the heating volume is large enough. This strategy provides a simple implementation to perform "on-line feedback" control in ultrasound thermal therapy.

\section{REFERENCES}

1. Fry W. J. et al.: Production of focal destructive lesions in the central nervous system with ultrasound, J. Neurosurgery 1954; 11: 471-478.

2. Hunt J. W. et al.: Rapid heating: critical theoretical assessments of thermal gradients found in hyperthermia treatments. Int. J. Hyperthermia 1991; 7: 703-718.
3. Sibille A. et al.: Extracorporeal ablation of liver tissue by high-intensity focused ultrasound. Oncology, 1993; 50: 375-379.

4. Sibille A. et al.: Characterization of extracorporeal ablation of normal and tumor-bearing liver tissue by high intensity focused ultrasound. Ultrasound Med. Biol., 1993; 19: 803-813.

5. Vaughan M. G. et al.: Minimally invasive cancer surgery using focused ultrasound: A pre-clinical normal tissue study. Br. J. Radiology, 1994; 67: 267-274.

6. Damianou CA, Hynynen K: Focal spacing and near-field heating during pulsed high temperature ultrasound therapy. Ultrasound Med. Biol., 1993; 19: 777-787.

7. Damianou CA, Hynynen K: The effect of various physical parameters on the size shape of necrosed tissue volume during ultrasound surgery. J. Acoust. Soc. Am., 1994; 95: 1641-1649.

8. Damianou CA, Hynynen K, Fan X: Evaluation of accuray of a theoretical model for predicting the necrosec tissue volume during focused ultrasound surgery. IEEE Trans. Ultrason. Ferroelect. Freq. Contr., 1995; 42: 182-187.

9. Dunn F, Fry FJ: Ultrasonic threshold dosages for the mammalian central nervous system. IEEE Trans. Biomed. Eng., 1971; 18: 253-256.

10. Sapareto SA, Dewey WC: Thermal dose determination in cancer therapy. Int. J. Radiat. Oncol. Biol. Phys., 1984; 10: 787-800.

11. Hutchinson EB, Hynynen K: Intracavitary Ultrasound Phased Arrays for Noninvasive Prostate Surgery. IEEE Trans. Ultrason., Ferroelect., Freq. Contr., 1996; 43: 1032-1042.

12. Lin WL et al.: Relationship between acoustic aperture size and tumor conditions fore external ultrasound hyperthermia. Med. Phys., 1999; 26: 818-824.

13. Drewniak JL, Frizzell LA, Dunn F: Errors resulting from finite beamwidth and sample dimensions in the determination of the ultrasonic absorption coefficient. J. Acoust. Soc. Am., 1990; 88: 967977.

14. Hynynen $\mathrm{K}$ : The feasibility of interstitial ultrasound hyperthermia. Med. Phys., 1992; 19: 979-987.

15. Diederich CJ: Ultrasound applicators with integrated catheter-cooling for interstitial hyperthermia: theory and preliminary experiments. Int. J. Hyperthermia, 1996; 12: 279-297.

16. Sanghvi NT et al. Noninvasive surgery of prostate tissue by high-intensity focused ultrasound. IEEE Trans. Ultrason. Ferroelec. Freq. Contr., 1996; 43: 1099-1110.

17. Lin WL et al.: Optimization of power deposition and a heating strategy for external ultrasound 
thermal therapy. Med. Phys., 2001; 28: 2172-2181.

18. Foster FS, Hunt JW: Transmission of ultrasound beams through human tissue-focusing and attenuation studies. Ultrasound Med. Biol., 1979; 5: $257-268$

19. Pennes HH: Analysis of Tissue and Arterial Blood Temperatures in the Resting Human Forearm. J. Appl. Phys., 1948; 1: 93-122.

20. Chato JC: Fundamentals of bioheat transfer. In Thermal Dosimetry Planning. M. Gautherie (Ed), Berlin: Sringer-Verlag, 1990.

21. Roemer RB: Thermal dosimetry. In Thermal Dosimetry Planning. M. Gautherie (Ed), SpringerVerlag, 1990.

22. Arkin H, Xu X, Holmes KR: Recent developments in modeling heat transfer in blood perfusion tissues. IEEE Trans. Biomed. Eng., 1994; 41: 97107.
23. Jain RK: Bioheat transfer: Mathematical models of thermal systems. In Hyperthermia in Cancer Therapy. Storm F. K. (Ed), Boston: G. K. Hall, 1983.

24. Dewey WC: Arrhenius relationships from the molecules and cell to the clinic. Int. J. Hyperthermia, 1994; 10: 457-483.

25. Pearce J, Thomsen S: Rate process analysis of thermal damage. In Optical-Thermal Response of Laser-Irradiated Tissue. Welch A. J. and van Gemert M. J. C. (Ed), New York Plenum, 1995.

26. Diederich CJ, Burdette EC: Transurethral ultrasound array for prostate thermal therapy: initial studies. IEEE Trans. Ultrason. Ferroelec. Freq. Contr., 1996; 43: 1011-1022.

27. ter Haar GR, Sinnett D, Rivens I: High intensity focused ultrasound -a surgical technique for the treatment of discrete liver tumours. Phys. Med. Biol., 1989; 34: 1743-1750. 